\title{
A QUANTITATIVE METHOD FOR THE ESTIMATION OF PEPSIN
}

By W. SCOTT POLLAND AND ARTHUR L. BLOOMFIELD

(From the Department of Medicine, Stanford University Medical School, San Francisco)

(Received for publication October 8, 1928)

The quantitative estimation of ferments is beset by many difficulties which do not obtain in the case of substances which can be directly weighed or measured. Since, in the present state of our knowledge, ferments can only be recognized through their effects, and since these effects vary greatly with many conditions, it has been difficult to develop standard methods which possess reasonable accuracy and at the same time are not too cumbersome.

The effects of ferment action vary with the time over which the reaction proceeds, the concentration of the substrate and the concentration of the enzyme as well as with other factors. Most of the methods have been based on the principle of varying one factor while others are kept constant, and the strength of the enzyme is usually expressed in terms of the degree to which the substrate has been effected. The details of the many procedures which have been devised may be read in Oppenheimer's elaborate treatise (1) or in the briefer compendium of Waksman and Davison (2). With regard to pepsin the usual procedure has been to allow decreasing quantities of ferment (gastric juice) to act on a uniform amount of substrate (such as a soluble protein) over a standard length of time and to determine the smallest amount of ferment which completely digests (as digestion may be defined) the unit of substrate. Thus, if $0.01 \mathrm{cc}$. of ferment completely digests the unit of substrate it is assumed that $1 \mathrm{cc}$. of ferment has the power of digesting 100 units. As various workers have shown, however, this assumption is entirely erroneous (3) since activity does not vary in direct proportion to the concentration of ferment. Methods based on this general plan must therefore be discarded. Northrup and Hussey recently have pointed out (4) that the time required to cause a given percentage change in the viscosity 
of a solution of substrate is nearly inversely proportional to the amount of enzyme present. On this basis they have developed a practical method for the measurement of peptic or tryptic activity. Special precautions are necessary, however, in the preparation of the substrate.

The present method, which was devised during the course of studies of peptic activity of gastric juice subsequently to be reported, is in accord with the established principles of ferment action and in practice has been found to be reasonably simple and accurate. In brief, increasing dilutions of ferment (gastric juice) are allowed to act on a uniform amount of substrate (soluble protein) for a uniform length of time (one-half hour at $37^{\circ} \mathrm{C}$ ). Instead of determining the greatest dilution which gives complete digestion the percentages of substrate digested by various dilutions of ferment are estimated. From these figures a curve can be constructed which shows at its peak the maximum degree of ferment activity under the conditions of the experiment.

\section{PROCEDURE}

A standard solution of protein (substrate) is prepared as follows: 2 grams of edestin (Special Chemicals Company, Waukegan, Ill.) are placed in a small beaker. To this is added, without stirring, 50 cc. of $0.3 \mathrm{~N}$ hydrochloric acid. The mixture is placed in a water bath $\left(100^{\circ} \mathrm{C}\right.$.) for one-half hour. Occasionally a minute residue of undissolved edestin remains. This is filtered off with gauze and dissolved in $10 \mathrm{cc}$. of acid which is then added to the edestin already dissolved. A few drops of thymol blue are next introduced as indicator and $20 \mathrm{cc}$. $\mathrm{N} / 10$ barium hydroxide are added. The mixture is then placed in a $100 \mathrm{cc}$. volumetric flask which is filled to the $100 \mathrm{cc}$. mark by adding $\mathrm{N} / 100 \mathrm{HCl}$. The reaction is tested colorimetriclly and adjusted so that the final mixture is a 2 per cent solution of edestin with a pH of approximately 2.0. This mixture may be kept on ice apparently unaltered (see below) for at least several weeks. It should be well shaken before being used.

In a series of small test tubes increasing dilutions of ferment (gastric juice) in $\mathrm{N} / 100 \mathrm{HCl}$ are set up. The ratio of successive dilutions may be as 1:2:4, etc., or otherwise as desired. In any case the total 


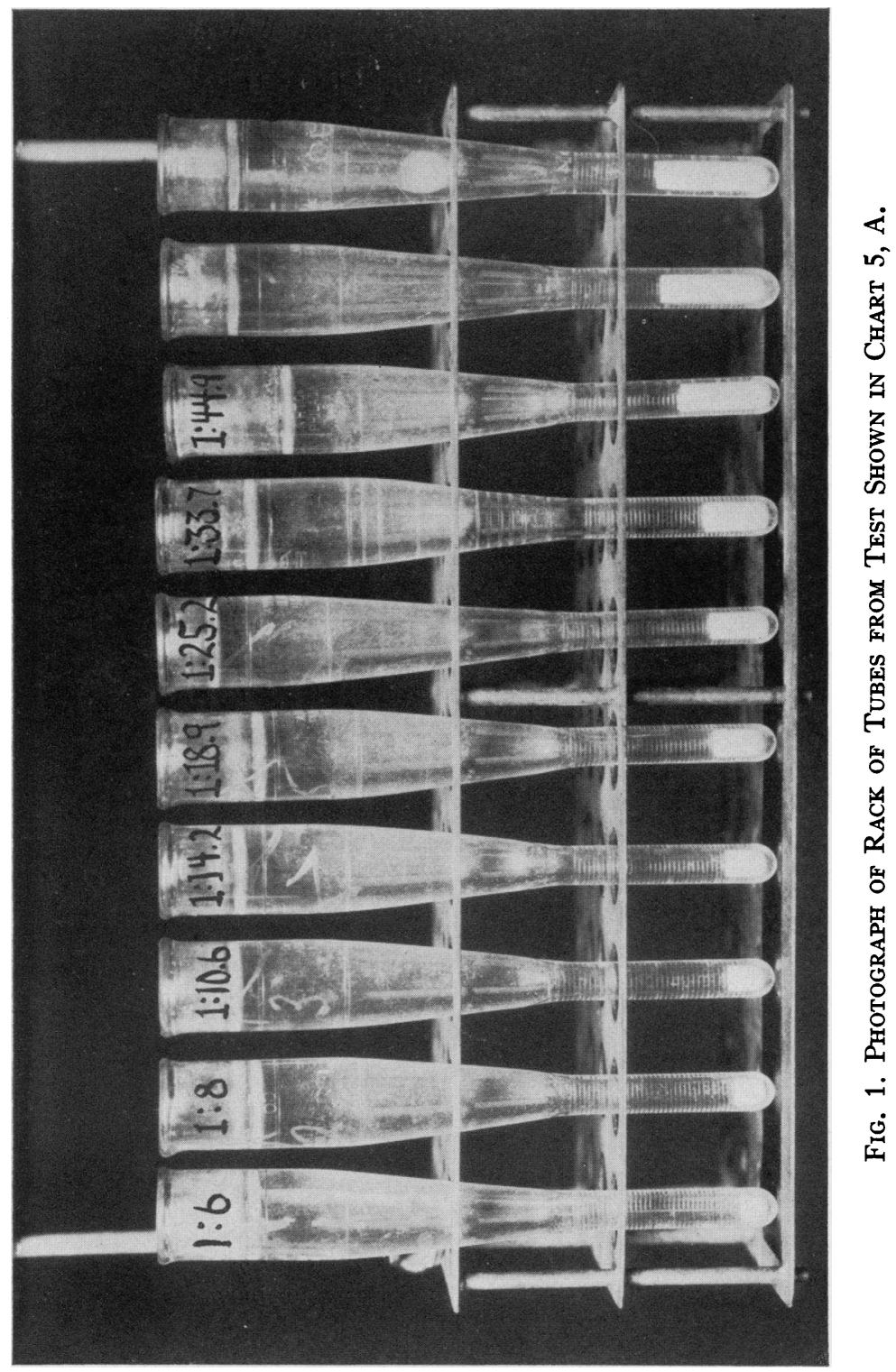


volume of diluted ferment in each tube is $1.0 \mathrm{cc}$. Five tubes containing $1.0 \mathrm{cc}$. of $\mathrm{N} / 100 \mathrm{HCl}$ but no ferment are added to the series as controls. To each tube $1 \mathrm{cc}$. of the edestin solution is next added and the tubes are then shaken and placed in the water bath at $37^{\circ} \mathrm{C}$. for exactly one-half hour. Throughout the procedure accurately calibrated volumetric pipettes are used and the digestion is carried out at approximately $\mathrm{pH} 2.0$. After incubation $1 \mathrm{cc}$. of 15 per cent trichloracetic acid is added to each tube. Unless complete digestion has taken place the remaining unsplit protein is precipitated. The contents of each tube are next transferred to a specially graduated centrifuge tube and the volume is made up to a total of $6.5 \mathrm{cc}$. The tubes have a capillary stem accurately graduated to $0.01 \mathrm{cc}^{1}$ The tubes are next allowed to stand for several hours or preferably over night at room temperature to allow swelling of the precipitate to come to an equilibrium and they are then centrifuged at 1600 revolutions for exactly 10 minutes. An automatic timing device attached to the centrifuge is very convenient. The bulk of the precipitate in the control tubes and in the test tubes is then read on the scale and the degree of digestion which has taken place with each dilution of ferment can be expressed in percentages in relation to the control. If, for example, the average of the control tubes which contained no ferment shows a precipitate to the 0.30 mark and if the tube containing $1 \mathrm{cc}$. of ferment shows precipitate to the 0.15 mark and if the control tube represented $300 \mathrm{mgm}$. of edestin, then $1 \mathrm{cc}$. of ferment has digested $\frac{0.15}{0.30}=\frac{1}{2}=150 \mathrm{mgm}$. of edestin. The calculations can best be demonstrated by an illustrative protocol.

Experiment 1. Increasing dilutions of a solution of commercial pepsin (Squibb's) in $\mathrm{N} / 100 \mathrm{HCl}$ were set up as shown in the protocol (table 1). To each tube $1 \mathrm{cc}$. of a 2 per cent solution of edestin in $\mathrm{N} / 100 \mathrm{HCl}$ was then added, the tubes were incubated in the water bath at $37^{\circ} \mathrm{C}$. for 30 minutes, trichloracetic acid was added and the tubes were centrifuged. The second column (readings of protein precipitated) shows the reading of the height of the undigested precipitated protein in the capillary stem of the graduated centrifuge tube. The figures in the third and fourth columns are self-evident.

${ }^{1}$ This tube devised by Dr. Thomas Addis for measuring small amounts of precipitate is made by the A. H. Thomas Company. (See fig. 1.) 


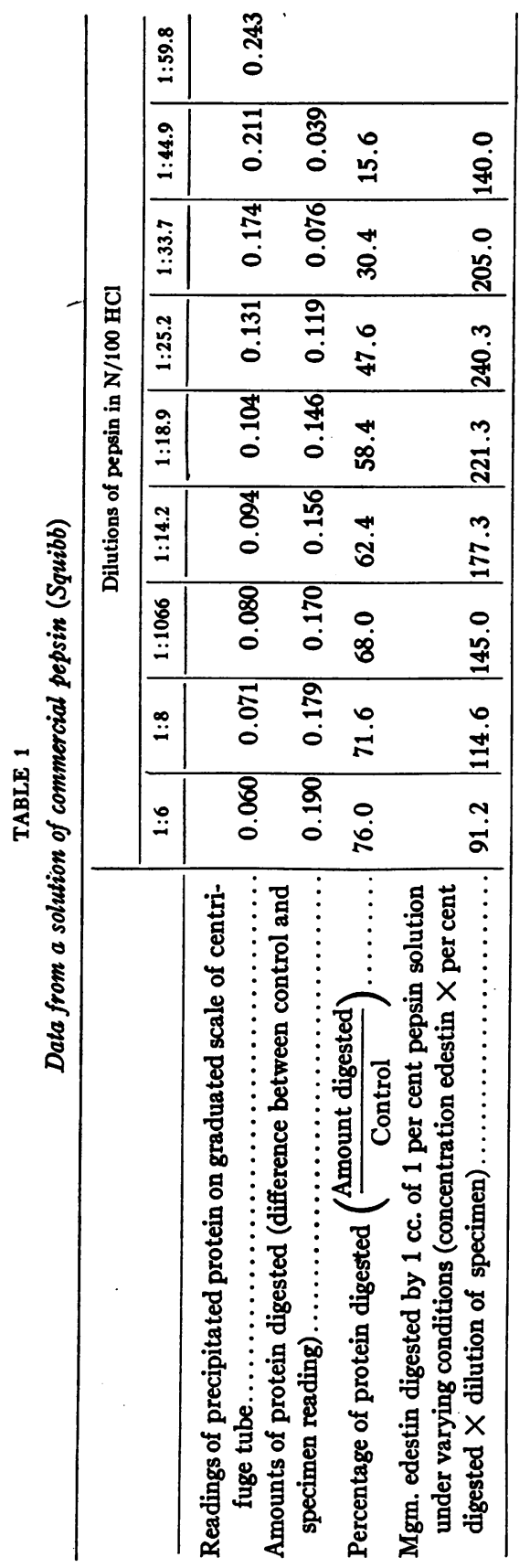




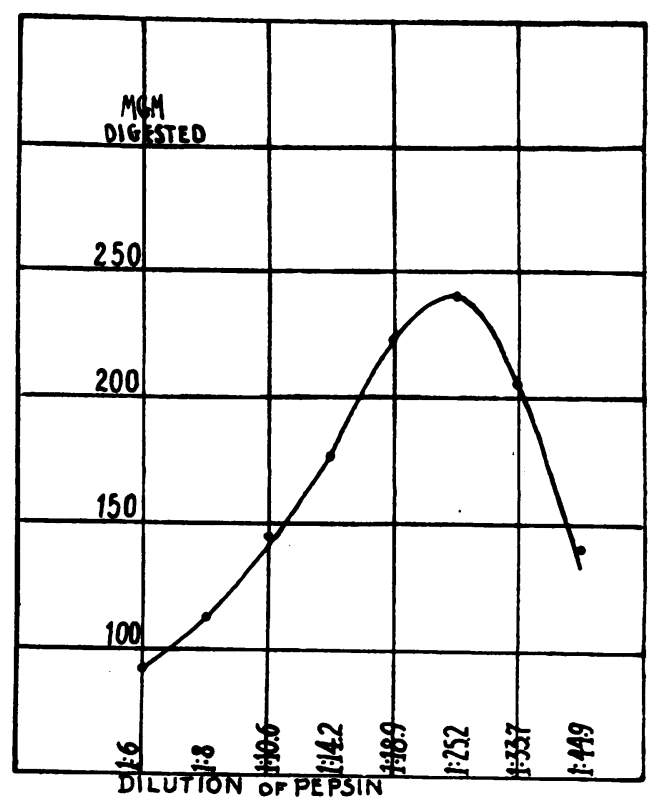

Chart 1. Curve Showing Amounts of Edestin (Mulligrams) Digested by 1 cc. of 1 Per Cent Pepsin Solution under Various Conditions of Dilution

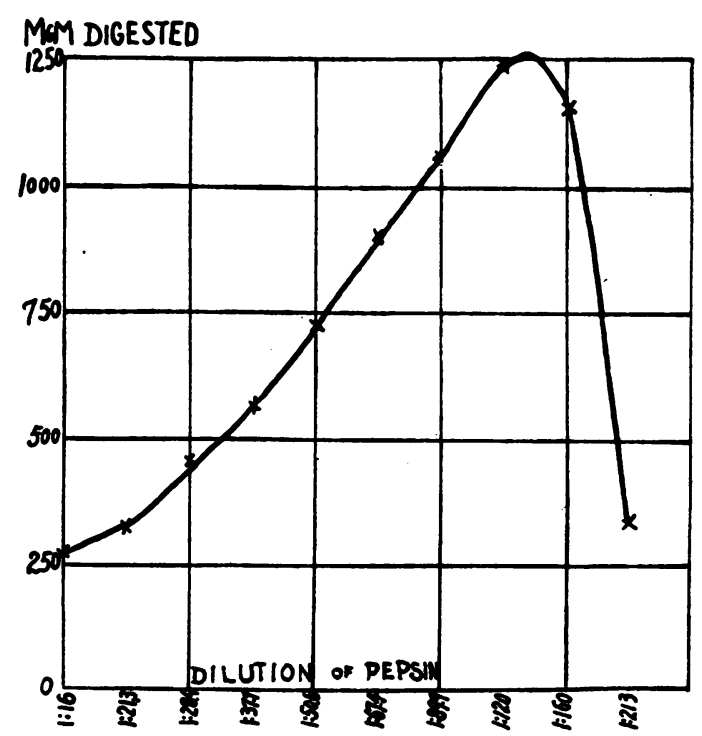

Chart 2. Curve Showing Amounts of Edestin (Mitligrams) Digested by 1 cC. OF Gastric JuICe under Various Conditions of DIIUTION 


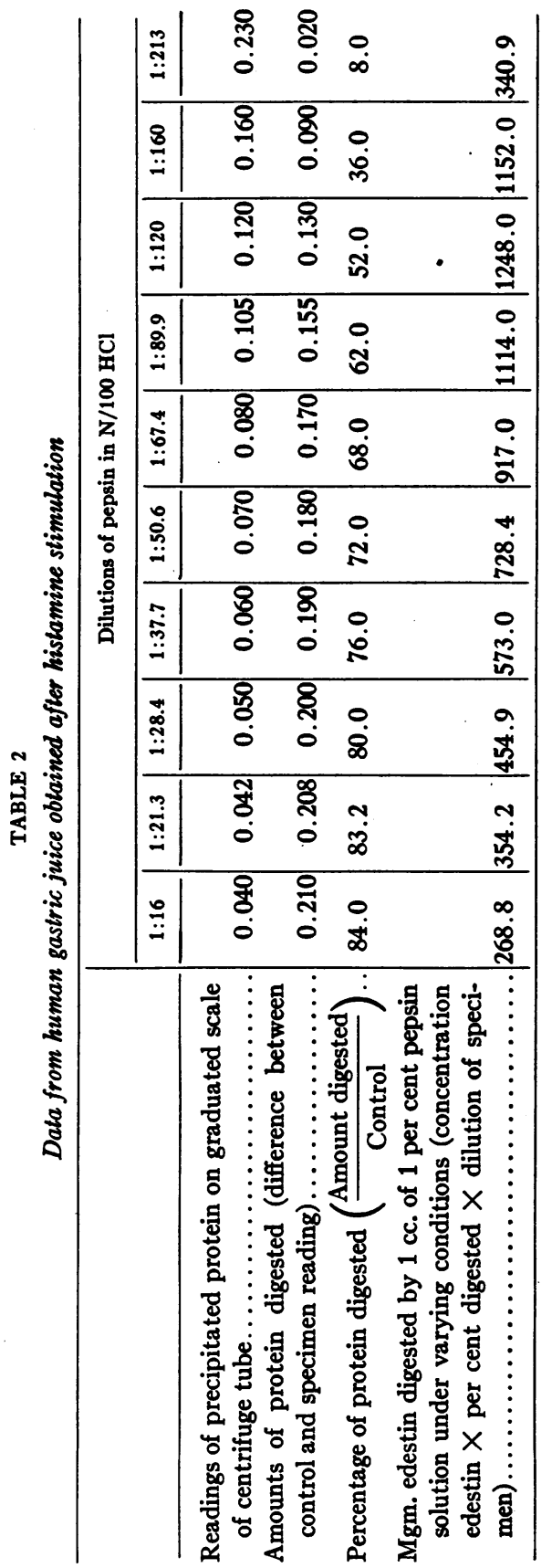


The last column gives the actual number of milligrams of edestin digested in each tube multiplied by the dilution of pepsin so that the final results are all expressed in terms of digestive power of $1 \mathrm{cc}$. of undiluted 1 per cent pepsin solution. They are shown graphically in chart 1 by plotting the total amount of edestin digested by $1 \mathrm{cc}$. of

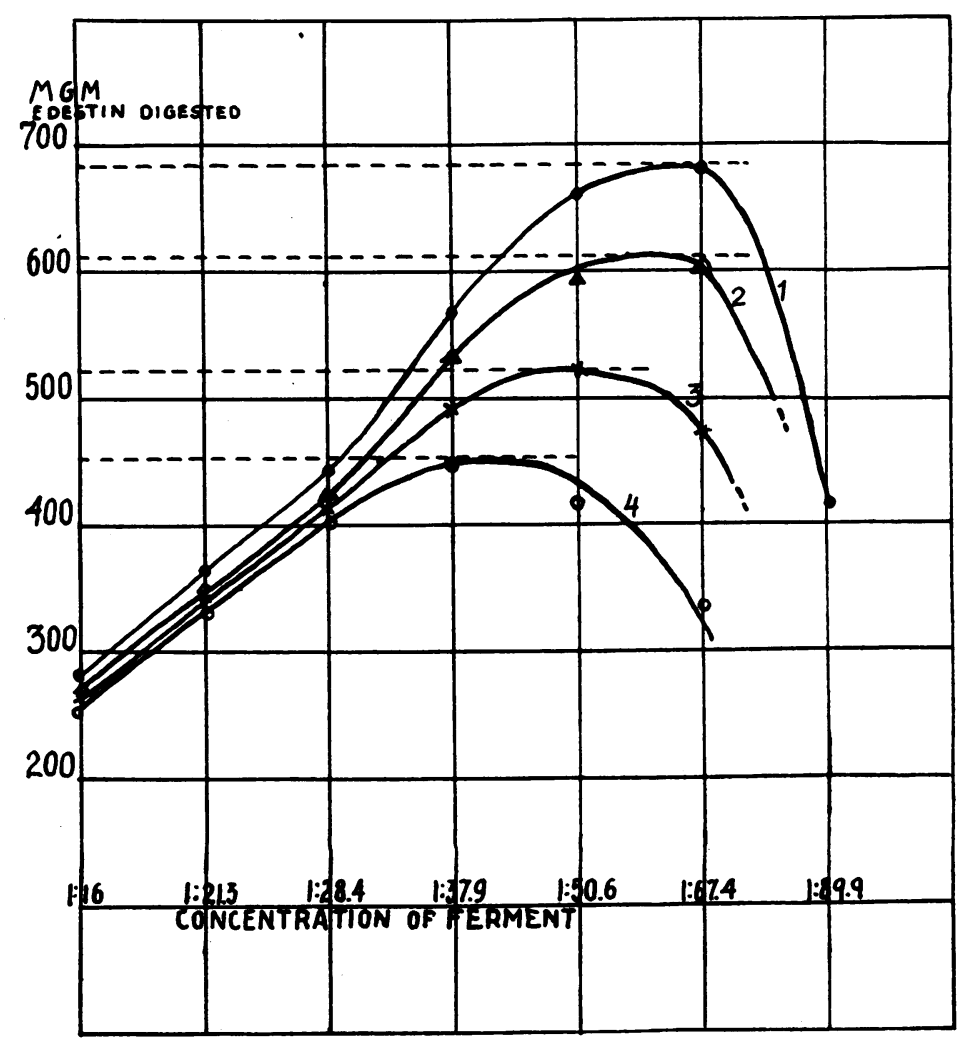

Chart 3. Curves Showing Titration of Pepsin in Gastric Juice Obtained Before and After Histamine Stimulation

pepsin in various dilutions against the dilution. It is evident that as the dilution of pepsin is increased relatively more digestion takes place until a certain optimum point (the peak of the curve) is reached. Beyond this peak further dilution of pepsin is followed by an abrupt lessening of digestive power. If one determines by the above method 
enough points to construct a curve it is evident that the high point will indicate the optimum digestive power of the specimen under consideration and will allow comparison with other specimens $\mathrm{ex}^{-}$ amined in the same way.

Experiment 2. Chart 2 and table 2 show the results of another experiment made with a specimen of gastric juice obtained after histamine stimulation from a normal human stomach. The shape of the curve is similar to that obtained in experiment 1 , and indicates that under optimum conditions $1 \mathrm{cc}$. of the gastric juice in question digests about $1250 \mathrm{mgm}$. of edestin. One cubic centimeter of a 1 per cent solution of commercial pepsin, on the other hand (experiment 1), digested only about $242 \mathrm{mgm}$. of edestin. The activity of the two specimens may therefore be compared, the relation being as $242: 1250$.

In work with normal human gastric juice we have found that in order to construct a satisfactory curve ten tubes are necessary, beginning with a dilution of $1: 16$ which is increased by $1 / 4$ in each successive tube. In anacidity cases in which pepsin is diminished it is necessary to begin with the undiluted juice, but increasing dilutions in the ratio of $1: 2$ are adequate. Chart 3 shows the results with specimens of pure gastric juice obtained from the same person before and after histamine stimulation. Curve 1 is from a specimen before histamine; curves 2, 3 and 4 are from specimens obtained 30, 40 and 50 minutes after histamine. The optimum digestive power of $1 \mathrm{cc}$. of juice from the various specimens is, in terms of milligrams of edestin, $682,611,521$ and 452 , figures which may be directly compared.

\section{CONTROL TESTS}

1. Repeated tests with the same substrate to test its stability. A lot of substrate was prepared according to the method outlined above. At weekly intervals it was tested against a solution of pepsin freshly prepared from the commercial powder. Chart 4 shows the results of the three tests which were practically identical. One may conclude that the substrate remains essentially unaltered over a period of at least two weeks.

2. Two lots of substrate were prepared and tested with the same pepsin solution at the same time. The results shown in chart 5 


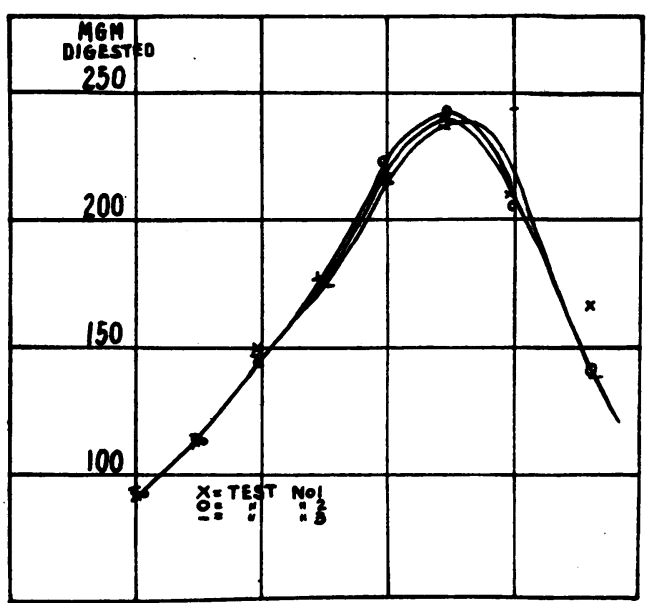

Chart 4. Titration of Pepsnn agannst the Same Lot of Substrate at Weekly INTERVALS

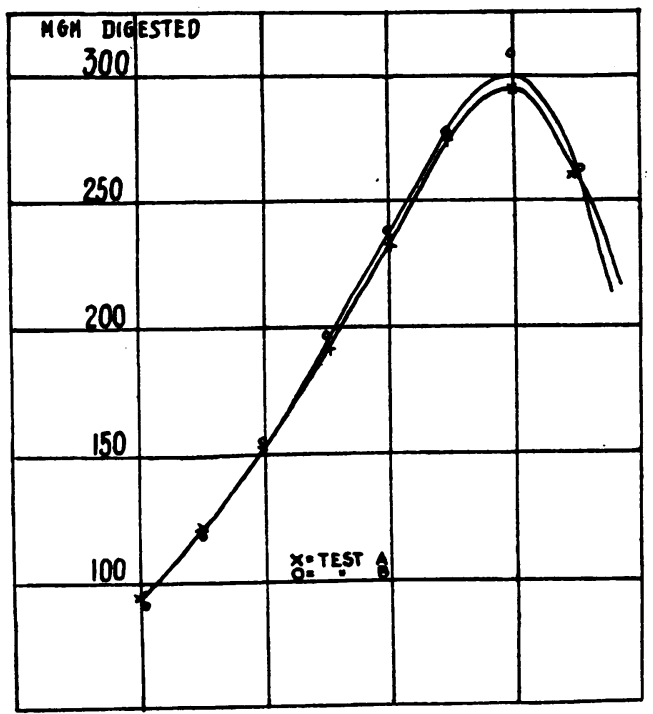

Chart 5. Titration of Pepsin against Two Lots of Substrate 
indicate that various lots of substrate are essentially identical and may therefore be used in comparative tests of peptic activity.

It is difficult to estimate in mathematical terms the exact degree of accuracy of the method. As is the case with all ferment titrations, unless the most accurate physical chemical methods are employed, a certain amount of error is unavoidable. Our controls indicate that this error is usually not over five per cent

\section{SUMMARY}

A method for comparing the peptic activity of specimens of gastric juice which eliminates certain fundamental errors of some of the older methods is described. In the following paper the results of the application of the method in the study of gastric physiology are exposed.

\section{BIBLIOGRAPHY}

1. Oppenheimer, C., Die Fermente und ihre Wirkungen. Vol. II. Leipsic, 1926.

2. Waksman, S. A., and Davison, W. C., Enzymes; Properties, Distribution, Methods and Applications. Baltimore, 1926.

3. Northrup, J. H., The Dynamics of Pepsin and Trypsin. The Harvey Lectures, 1925-26, p. 36.

4. Northrup, J. H., and Hussey, R. G., J. Gen. Physiol., 1922-23, v, 353. A Method for the Quantitative Determination of Trypsin and Pepsin. 